\title{
RESEARCH ON THE INFLUENCE OF VIRTUAL MODELING AND TESTING-BASED RUBBER TRACK SYSTEM ON VIBRATION PERFORMANCE OF ENGINEERING VEHICLES
}

\author{
Guo HaoLiang $^{1 *}-$ Mu XiHui $^{2}-$ Yang XiaoYong $^{3}-$ Lv Kai $^{4}$ \\ ${ }^{1}$ Department of Ammunition Engineering, Ordnance Engineering College, Shijiazhuang 050003, China \\ ${ }^{2}$ Ordnance Technology Research Institute, Shijiazhuang 050003, China \\ ${ }^{3}$ The Third Assembly Factory of First Tractor Company Limited, Luoyang 471004, China \\ ${ }^{4}$ Military Transportation University, Tianjin 300161, China
}

\begin{tabular}{l}
\hline ARTICLE INFO \\
\hline Article history: \\
Received: 03.04 .2016$. \\
Received in revised form: 27.06 .2016$. \\
Accepted: 13.07 .2016$. \\
\hline Keywords: \\
Rubber track system \\
ride comfort \\
Virtual modeling \\
Multi-body dynamic \\
Polygon effect \\
\hline
\end{tabular}

DOI: https://doi.org/10.30765/er.38.3.5

\begin{abstract}
:
The rubber track system can be quickly swapped on the tyres, exerting a smaller ground pressure while generating a greater adhesion to solve the problem vehicles faced in traversing rough and difficult terrain. This paper will discuss the influence of rubber track system on the ride comfort of engineering vehicles with rigid suspension. First, a multi-body dynamic model of the rubber track system and a mathematical model of contact between the ground and the track are established, and then the macro commands are programmed to add many complex contact forces. Moreover, by using the method of physical prototype obstacle testing, the correctness of the simulation model is validated. The ride comfort of the engineering vehicle when equipped with rubber track system is explored by the method of the multi-body dynamics and real vehicle test. The research shows that a flexible roller wheel system can significantly improve the ride comfort of the engineering vehicle when compared to wheeled vehicles. When the vehicle speed is low, the weighted root-meansquare acceleration of the wheeled vehicle and tracked vehicle is almost the same. At the same time, it is verified that the ride comfort of the steelchain tracked vehicles is worse than that of rubber tracked vehicles, due to the polygon effect. Through the multi-body dynamics simulation of the virtual prototype, we can predict and evaluate the ride comfort of vehicles, saving the cost of testing and obtaining the actual experimental data, which has great significance for the research and development of vehicles.
\end{abstract}

\footnotetext{
* Corresponding author. Tel.: +86031187974234

E-mail address: haocui876@163.com
} 


\section{Introduction}

The rubber track system, which can be rapidly swapped, is a special crawler device with both the characteristics of tyres and tracks. It is used to solve the problem the vehicle faced while traversing rough and difficult terrain, such as beaches, marshes, deserts, snow and gravel [1-3], as shown in Fig.1. Compared to the regular track, rubber track system can adapt to difficult terrain better and it enjoys a smaller turning radius. With more contact area and less ground pressure, the rubber track system enjoys obvious superiority over the ordinary tyres. With enhanced adhesion and improved traversing ability for vehicle to ride comfort on difficult terrain, as well as stable traction [4-7], the rubber track system is mainly composed of load wheels, dynamic guide wheels, a frame, an anti-torque system, a sprocket and a rubber track, as shown in Fig.2.

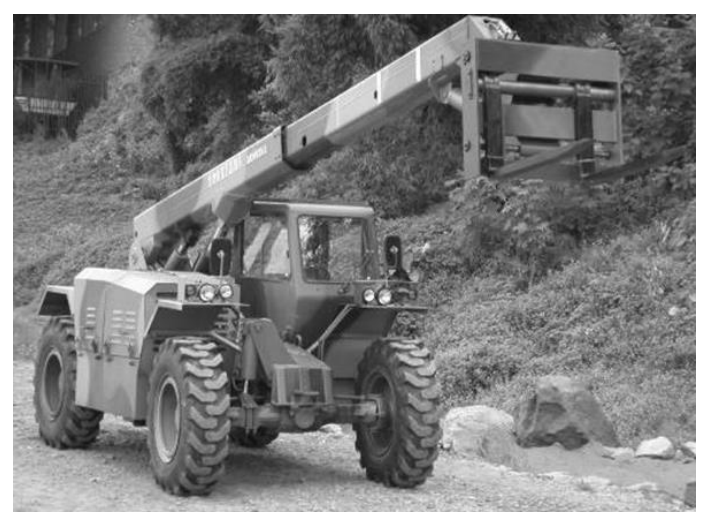

a) Before the vehicle equipped with rubber track system

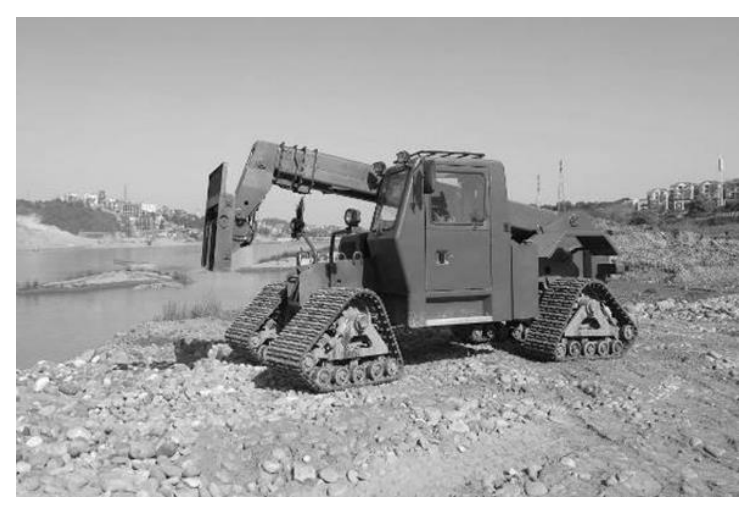

b) After the vehicle equipped with rubber track system

Figure 1. The comparison of the engineering vehicle when equipped with rubber track system.

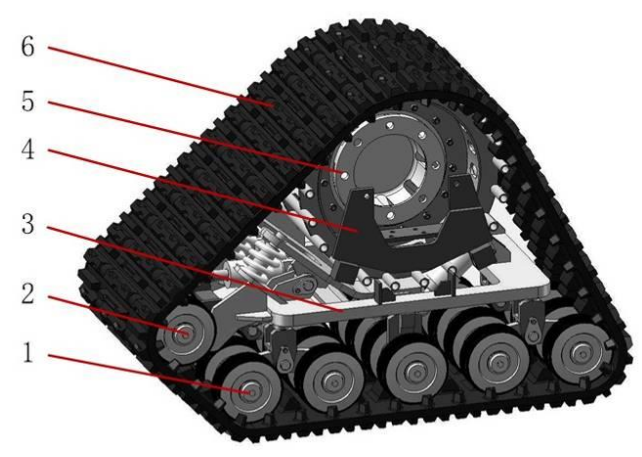

Figure 2. The composition of the rubber track system: 1 - Flexible roller wheel, 2 Dynamic guide wheels, 3 -Frame, 4 - Antitorque system, 5 - Sprocket, 6 - Rubber track.

Because of the rigid suspension, a ride comfort of the engineering vehicle is rather poor.Therefore, it is particularly important to study the vibration of the vehicle driving before and after the modification. According to the structure of load wheels, it can be divided into the following two categories: a) rigid roller wheels system, fixed on the frame, whose position does not change when the vehicle drives [8, 9]; b) flexible roller wheel system, hinged to the frame through suspension, which can swing with the terrain to make the rubber track better fit the terrain contour $[10,11]$. In the paper, the method of multibody dynamics and the real vehicle test are used to evaluate the difference between the effects of flexible roller wheel system of rubber track system and tyres on ride comfort of engineering vehicle. The difference between steel-chain tracked vehicles and rubber tracked vehicles is also compared.

\section{The Establishment of the multi-body dynamics model based on ADAMS}

\subsection{Establishing the Virtual prototype}

The method of virtual prototype simulation is often used in the performance simulation of vehicles, which determines errors in the theoretical calculation, and saves the cost of traditional physical prototype testing [12-14]. The Automatic Dynamic Analysis of Mechanical System (ADAMS) is one of the most common and authoritative dynamic analysis softwares of mechanical system in CAE field, which integrates modeling, solving, and visualization techniques. It can conduct the static, dynamic, and 
kinematic of the virtual prototype at the same time $[15,16]$.

Since the ADAMS modeling is obviously insufficient, especially for a complex model with a curved shape, the virtual prototype of the rubber track system is established in Solidworks. This can be imported into the ADAMS by IGS format after simplification[17, 18]. By being simplified, the mass of the virtual prototype is rather different from that of the physical one. Therefore, a matching block is fixed on the frame to adjust the mass and centroid position. Then, the constraints and kinematic pairs are added. In this model, in addition to the tensioning device and the central independent swing suspension between which the moving pair is added, there is the revolute pair added between almost all the other parts. The determination of model parameters of the rubber track system can be seen in Tab. 1 .

\section{Table 1. Determination of model parameters}

\begin{tabular}{|c|c|c|c|}
\hline Parameters & Signs & Values & Units \\
\hline Overall Length & $\mathrm{L}$ & 6590 & $\mathrm{~mm}$ \\
\hline Overall Width & $\mathrm{W}$ & 2340 & $\mathrm{~mm}$ \\
\hline Overall Height & $\mathrm{H}$ & 2390 & $\mathrm{~mm}$ \\
\hline Maximum Loads & $\mathrm{G}$ & 2500 & $\mathrm{~kg}$ \\
\hline Total Mass & $\mathrm{M}$ & 7990 & $\mathrm{~kg}$ \\
\hline Front Drive axle Mass & $\mathrm{M}_{1}$ & 2560 & $\mathrm{~kg}$ \\
\hline Rear Drive axle Mass & $\mathrm{M}_{2}$ & 3707 & $\mathrm{~kg}$ \\
\hline Load Center Distance & $\mathrm{h}_{1}$ & 600 & $\mathrm{~mm}$ \\
\hline $\begin{array}{c}\text { Minimum Ground } \\
\text { Clearance }\end{array}$ & $\mathrm{h}_{2}$ & 400 & $\mathrm{~mm}$ \\
\hline Maximum Speed & $\mathrm{S}$ & 15 & $\mathrm{Km} / \mathrm{h}$ \\
\hline Tire Width & $\mathrm{W}_{\mathrm{T}}$ & 350 & $\mathrm{~mm}$ \\
\hline Tire Radius & $\mathrm{R}_{\mathrm{T}}$ & 650 & $\mathrm{~mm}$ \\
\hline Rubber track Width & $\mathrm{RW}$ & 600 & $\mathrm{~mm}$ \\
\hline
\end{tabular}

\subsection{The contact mathematical model and program macro commands}

The rubber track system uses rubber track. Unfortunately, there is no dynamic simulation environment for rubber track.

Therefore, many hinged steel track are linked to simulate the rubber track.

In the virtual modeling of rubber track system, the key point is applying all kinds of forces, which are mainly the contact force between different components. Meanwhile, the motion relationship of components is defined by various constraints. In the ADAMS/View, if there are no contact force between the various components of the rubber track system, there will be a direct influence caused by each other, so the contact force should be added[18-20].
The Impack function is adopted to establish the contact mathematical models between the track and the ground. The format is that:

$$
\operatorname{IMPACT}\left(q, \dot{q}, q_{1}, q, k, e, c_{\text {max }}, d\right)
$$

where $\boldsymbol{q}$ is a variable of contact distance, and it is used to define the distance between the two points of contact; $\boldsymbol{q}_{\boldsymbol{1}}$ is a threshold of the Impack function, whose value is of 0.3 . When $\boldsymbol{q}>\boldsymbol{q}_{1}$, Impack $=0$, and when $\boldsymbol{q}<\boldsymbol{q}_{1}$, Impack $\neq 0 . \boldsymbol{k}$ is the stiffness coefficient, with the value of $1.0 \mathrm{E}+005 \mathrm{~N} / \mathrm{m}$. $\boldsymbol{e}$ is the force exponent, and its value is of 2.2. $\boldsymbol{c}_{\max }$ is the damping coefficient, whose value is of 10.0. $\boldsymbol{d}$ is the penetration depth, and its value is of 10.0.

$$
\begin{aligned}
\text { IMPACT } & =\left\{\begin{array}{c}
0, q>q_{1} \\
k\left(q_{1}-q\right)^{e}-c_{\max } \dot{q} \times \\
\times \text { step }\left(q, q_{1}-d, 1, q_{1} 0\right), q \leq q_{1}
\end{array}\right. \\
& =\left\{\begin{array}{c}
0, q>0.3 \\
10^{5}(0.3-q)^{2.2}-10 \dot{q} \times \\
\times \text { step }(q, 0.2,1,0.3,0), q \leq 0.3
\end{array}\right.
\end{aligned}
$$

There are many track treads in the rubber track system. When the vehicle moves, many contact forces will be produced between each track tread and the ground, road wheel, and driving wheel. Therefore, using the conventional method of applying a contact force one by one is not only inaccurate, but also difficult to realize.

In this paper, macro commands of ADAMS are adopted to add variety and complex contact forces $[21,22]$. The parameters required for the calculation of contact forces are shown in Tab. 2.

Taking the contact force between track tread and ground as an example, the macro commands are as follows. The contact force between track tread and other parts can be modified to bold fonts:

variable set variable_name $=\$$ _self.num integer $=1$

for variable_name $=b b b$ start $=1$ end $=\mathbf{3 4}$

interface command_builder

interface dialog execute dialog=.gui.contact_cre undisplay=yes

contact create \&

contact_name=.MODEL_1.(eval("contact_ground_ "//\$_self.num)) \&

adams_id $=\left(\right.$ eval $\left.\left(\$ \_s e l f . n u m+5000\right)\right) \&$

i_geometry_name=.MODEL_1.(eval("tracklink1_"//

\$_self.num)).shell1 \&

$j \_$geometry_name $=. M O D E L \_1$. ground.BOX_348\& 
stiffness $=35000 \&$

damping $=35 \&$

$d \max =0.1 \&$

exponent $=1.5 \&$

augmented_lagrangian_formulation $=$ no $\quad \&$

coulomb_friction $=$ on $\&$

mu_static $=0.4 \quad \&$

mu_dynamic $=\mathbf{0 . 3} \&$

stiction_transition_velocity $=0.1 \&$

friction_transition_velocity $=\mathbf{1 . 0}$

variable set variable_name $=\$$ _self.num integer $=\left(\right.$ eval $\left(\$ \_\right.$self.num +1$\left.)\right)$

end

variable delete variable_name $=\$$ _self.num

Table 2. Parameters required for the calculation of contact forces

\begin{tabular}{|c|c|c|c|}
\hline Parameters & $\begin{array}{c}\text { Track treads } \\
\text { between } \\
\text { driving wheel }\end{array}$ & $\begin{array}{c}\text { Track treads } \\
\text { between } \\
\text { road wheels }\end{array}$ & $\begin{array}{c}\text { Track } \\
\text { treads } \\
\text { between } \\
\text { ground and } \\
\text { wheel }\end{array}$ \\
\hline Rigidity & $1.0 \mathrm{E}+007$ & $1.0 \mathrm{E}+006$ & $3.5 \mathrm{E}+004$ \\
\hline Damping & 10000 & 1000 & 35 \\
\hline $\begin{array}{c}\text { Force } \\
\text { Exponent }\end{array}$ & 2.2 & 2.2 & 1.5 \\
\hline $\begin{array}{c}\text { Penetration } \\
\text { Depth }\end{array}$ & $1.0 \mathrm{E}-004$ & $1.0 \mathrm{E}-003$ & $1.0 \mathrm{E}-003$ \\
\hline $\begin{array}{c}\text { Coulomb } \\
\text { Friction }\end{array}$ & On & On & On \\
\hline $\begin{array}{c}\text { Static } \\
\text { Coefficient }\end{array}$ & 0.15 & 0.2 & 0.4 \\
\hline $\begin{array}{c}\text { Dynamic } \\
\text { Coefficient }\end{array}$ & 0.1 & 0.15 & 0.3 \\
\hline Stiction Vel. & 0.1 & 0.1 & 0.1 \\
\hline $\begin{array}{c}\text { Friction } \\
\text { Vel. }\end{array}$ & 1.0 & 1.0 & 1.0 \\
\hline
\end{tabular}

\section{Verify the correctness of the simulation model by testing}

To verify the correctness of the virtual prototype model, the methods of testing and virtual simulation are used.

\subsection{Physical prototype testing}

A vibration sensor is fixed at one end of the drive axle that's equipped with rubber track system, as shown in Fig.3. A portable dynamic signal recorder (DSMINITAUR) is adopted to collect data.

In the test, the vehicle is moving slowly on the road with different obstacles when the vibration acceleration of the rubber track system is measured, as shown in Fig.4.

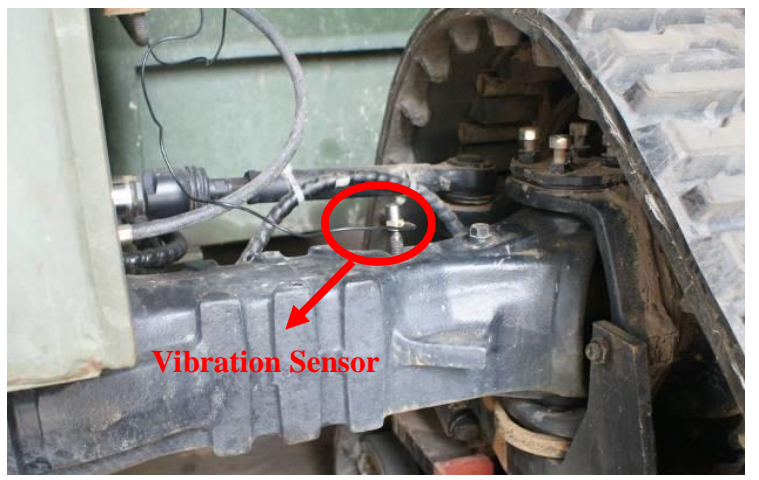

Figure 3. A vibration sensor is fixed at one end of the drive axle

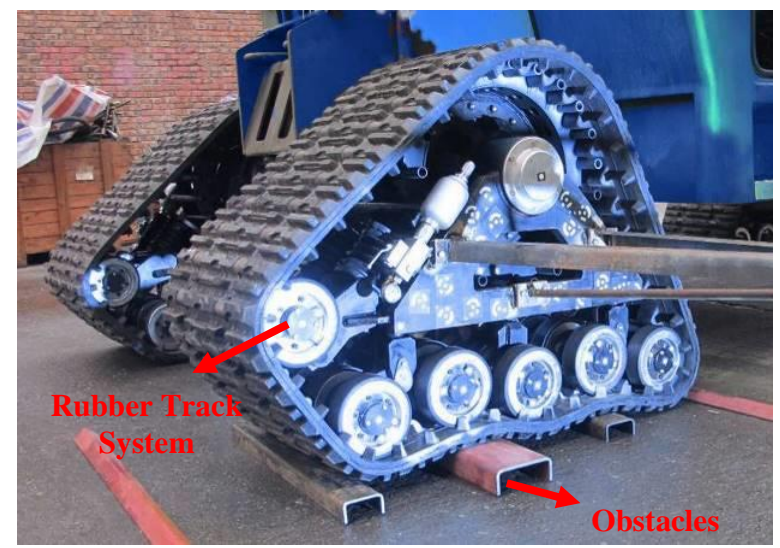

Figure 4. Physical prototype obstacle testing

\subsection{Multi-body dynamic simulation of virtual prototype}

In the ADAMS (Fig. 5),obstacles are arranged according to the arrangement of those in the obstacle test, and the multi-body dynamic simulation is conducted based on the above established virtual prototype model. Then, in terms of the position of the vibration sensor in the obstacle test, a MARKER point is established on one side of the drive wheel, and it is fixed to the drive wheel for the measurement of the vibration here afterwards.

\subsection{Comparison between the test and simulation data}

The unit of the data obtained in physical prototype testing and virtual prototype simulation is unified with that of the acceleration to be " $\mathrm{m} / \mathrm{s}^{2}$ ". Using timedomain analysis, an acceleration response curve is established, as shown in Fig.6. 


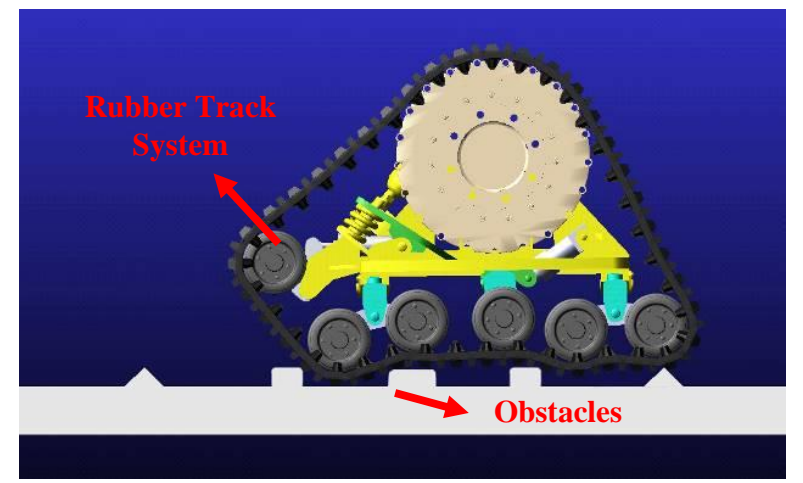

Figure 5. Multi-body dynamic simulation of virtual prototype.

It can be seen from Fig. 6 that when the rubber track system traverses different obstacles, the acceleration response curves of prototype testing and virtual simulation are nearly the same. Therefore, we conclude that the multi-body dynamic simulation model is valid.

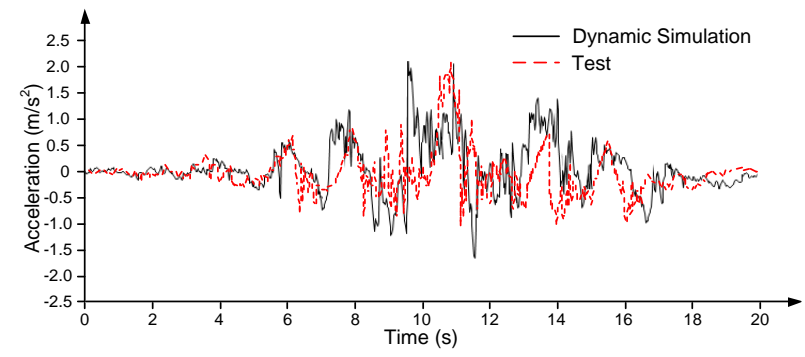

Figure 6. Acceleration response curve in timedomain.

\section{Simulation and the ride comfort test of engineering vehicles equipped with the rubber track system}

\subsection{The test introduction}

In the paper, the method of multi-body dynamics and real vehicle test are used to evaluate the difference between the influence of flexible roller wheel system of rubber track system and tyres on the ride comfort of engineering vehicle. In the test, asphalt roads or concrete roads satisfying the standard of national secondary road should be used. The two ends of the test roads are set up with $30-50 \mathrm{~m}$ long acceleration zone, and obvious signs should be built in the steady speed zone. A prototype achieves the required speed before entering the steady speed zone, and then traverses the zone by uniform speed [23]. The vibration acceleration sensor is installed in the center of the cab seat, and the data is collected by the DEWESoft's portable dynamic signal recorder, as shown in Fig.7.

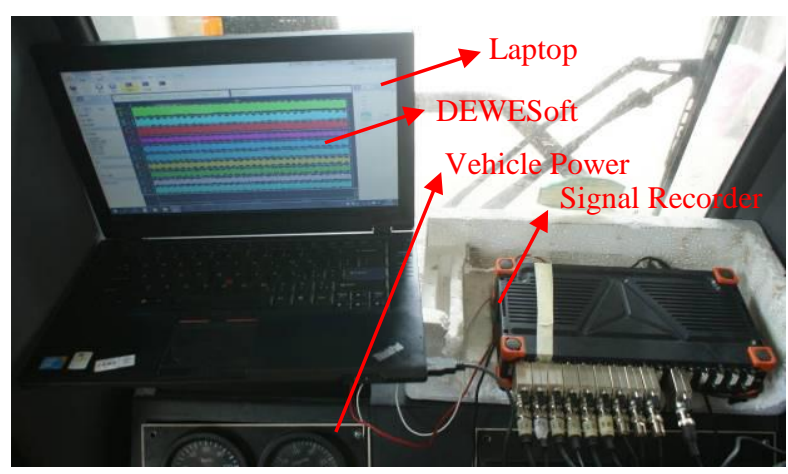

Figure 7. The vibration acceleration data acquisition system.

\subsection{Introduction to the simulation model setting}

The virtual simulation analysis is carried out under the same conditions as the real vehicle test. The drive axle and the four track systems are established in the simulation model of tracked vehicle. The drive axle and the four tyres are established in the simulation model of wheeled vehicle. Meanwhile, the tire used UA model, and the road used the stationary random road model [24]. Moreover, the matching block is added for the model, and a MARKER point is created in the center of the cab seat to measure the vertical vibration acceleration of the point, and then the weighted root-mean-square acceleration is compared with the test results.

\subsection{The comparative analysis of simulation and the test results}

The vertical vibration acceleration data is transformed into frequency domain, and then the $1-80 \mathrm{~Hz}$ frequency range is divided into 20 frequency bands by $1 / 3$ frequency doubling method. After that, the effective values of the vibration acceleration in each frequency band are weighted to get the root-mean-square acceleration.

It can be seen in Figure 8 that the comparison of the test and simulation results of weighted root- 
mean-square acceleration for the center of the cab seat when the engineering vehicle drives straightly(with engine speed of $2397 \mathrm{r} / \mathrm{min}$ ) at the first gear $(5 \mathrm{~km} / \mathrm{h})$, the second gear $(10 \mathrm{~km} / \mathrm{h})$ and the third gear $(15 \mathrm{~km} / \mathrm{h})$ speed respectively.

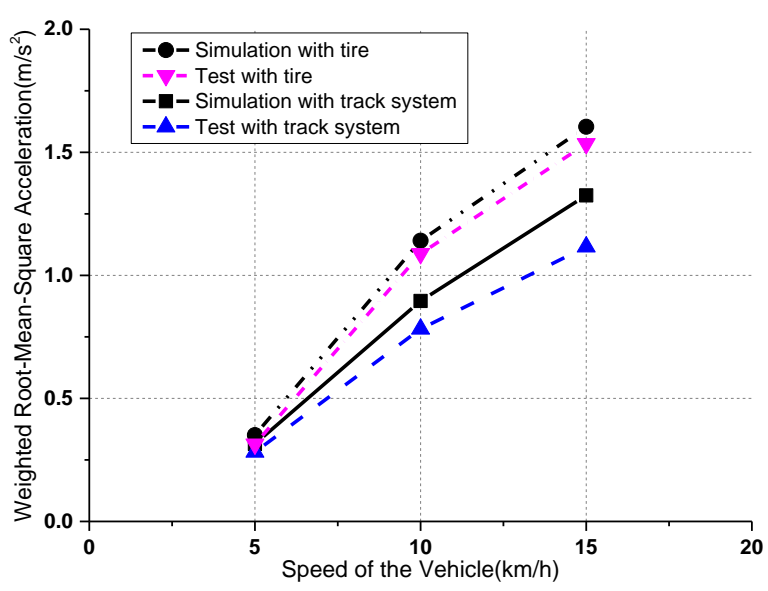

Figure 8. Comparison of the ride comfort test and simulation results.

As it can be seen from Fig.8, the simulation results agree well with the experimental results. Thus, the reasonability of the established vehicle dynamics model is verified. At different speeds, the weighted root-mean-square acceleration of the tracked vehicle is always smaller than that of the wheeled vehicle. According to the national standard GB/T4970-2009 [25], the ride comfort of tracked vehicle is better than that of wheeled vehicle. Therefore compared to wheeled vehicles, the flexible roller wheel system can significantly enhance the ride comfort of the engineering vehicle.

When the vehicle speed is low, the ride comfort of the wheeled vehicle and tracked vehicle is almost the same. However, the ride comfort of the vehicle becomes worse with the increase of the vehicle speed, which is more obvious for wheeled vehicles. Fig.9 and Fig.10 demonstrate the test and simulation results of vertical vibration acceleration of the center of cab seat of tracked vehicle and wheeled vehicle driving at the third gear, respectively.

From Fig.9 and Fig. 10, it can be seen that the amplitude range and mean value of the test and simulation are basically consistent with the time domain comparison of the wheeled and tracked vehicle acceleration signals. However, there are small errors in the simulation, and the error of Fig.9 is relatively smaller. On the one hand, the error is caused by the simplification of some components when establishing the simulation model. On the other hand, it is caused by the difference between the built terrain and the actual one. In Fig.10, the error is larger because of the additional vibration caused by the polygon effect of track links and the change of material from rubber to steel. Moreover, the higher the speed, the more obvious the polygon effect, and the worse the ride comfort. This is the reason why the ride comfort of the steel-chain tracked vehicles is worse than that of the rubber tracked vehicles.

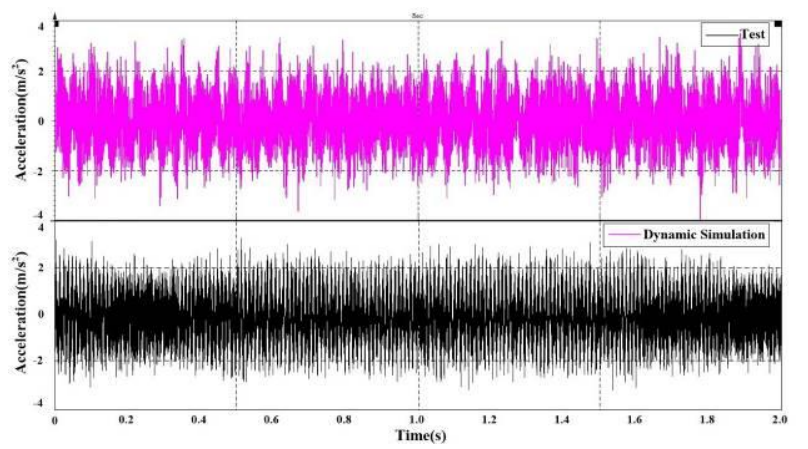

Figure 9. Vertical vibration acceleration curve of cab seat of wheeled vehicle.

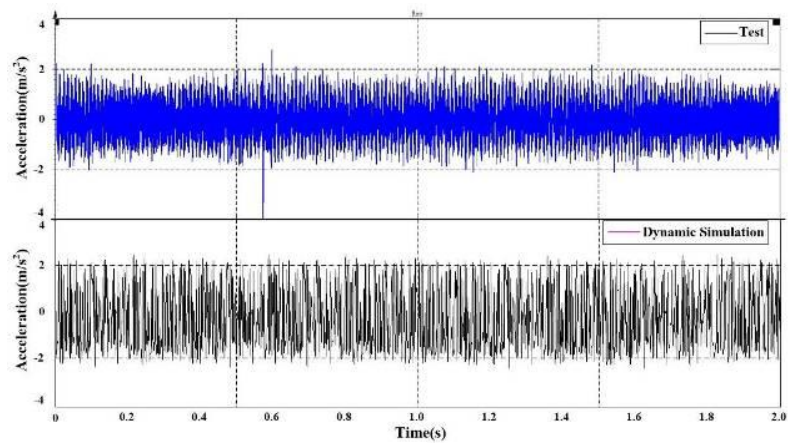

Figure 10. Vertical vibration acceleration curve of cab seat of tracked vehicle.

\section{Conclusion}

In the paper, a virtual simulation model of the rubber track system is established based on the multi-body dynamic software. The model basically reflects the 
kinematics and dynamics of the real vehicle, and the correctness of the model is validated by the real vehicle test. Moreover, the test results can be used to predict and evaluate the ride comfort of the vehicle. Through the research of this paper, the idea of virtual simulation based on physical prototype is applied to actual vehicles, which can not only save the cost of the test, but it can also acquire the data consistent with those acquired by the actual tests. Therefore, it is feasible to analyze the performance of the tracked vehicle by virtual prototype, which has important significance on the research and development of the tracked vehicle.

Meanwhile, the virtual prototype simulation and the real vehicle test show that the ride comfort of engineering vehicles equipped with the rubber track system is better than that of the wheeled vehicle. The research shows that compared to the wheeled vehicles, a flexible roller wheel system can significantly improve the ride comfort of the engineering vehicle. When the vehicle speed is low, the weighted root-mean-square acceleration of the wheeled vehicle and tracked vehicle is almost the same. However, with the increase of the vehicle speed, the ride comfort of the vehicle becomes worse, which is more obvious for the wheeled vehicle. In the simulation model, because the rubber track is divided into a number of steel track links, leading to the polygon effect, the ride comfort is worse than that of the real vehicle. Moreover, the higher the speed, more obvious the polygon effect, and worse is the ride comfort. Thus, this is the reason why the ride comfort of steel-chain tracked vehicles is worse than that of the rubber tracked vehicles.

\section{Acknowledgment}

The authors would like to acknowledge the financial support from the National Natural Science Foundation of China (Grant No. 61471385). The authors are grateful to the anonymous reviewers for valuable comments and suggestions, which helped to improve this study.

\section{References}

[1] Hu, Z. N.: Optimization Design in the Driving Gear Wheel Axle of Triangular Rubber Track Conversion, Advanced Materials Research, 308310 (2011), 513-516.

[2] Zhongming, H., Kai, Y., Shengjun, W.: Development and Application of replaceable rubber track system, China Rubber Industry, 56 (2009), 12, 764-767.

[3] LiHao, Y., ShengJun, W., YouJun, W.: Status and Developing Tendency of Tracked Wheel Conversion Technology, Development \& Innovation of Machinery \& Electrical Products, 24 (2011), 2, 80-82.

[4] Brazier, G.: Belted track assembly, US Patent 528133 S, Sept. 12, 2006.

[5] Hansen, R. S.: Apparatus for converting a wheeled vehicle to a tracked vehicle, US Patent 8827013, 2014-09-09.

[6] Hansen, R. S.: Apparatus for Converting a Wheeled Vehicle to a Tracked Vehicle, U.S. Patent 478808 B2, Sept. 05, 2014.

[7] Bessette, R.: Traction assembly with endless track having variable ground-contacting area, US Patent 8007058 B2, Aug. 30, 2011.

[8] Christianson, P.: Track system for a ground engaging vehicle, US Patent 7222924, 2007-0329.

[9] Bessette, R. L. F.: Traction assembly, US Patent 8240782, 2012-08-14.

[10] Brazier, G.: Track drive assembly, US Patent 8152248, 2012-04-10.

[11] Nagorcka, J. A., Allen, L. D.: Track suspension, EP Patent 2727803, 2014-05-07.

[12] Wang, J., Chen, J., Ouyang, S., Yang, Y.: Trajectory tracking control based on adaptive neural dynamics for four-wheel drive omnidirectional mobile robots, Engineering Review, 34 (2014), 3, 235-243.

[13] Li, Y., Frimpong, S.: Dynamic modelling and virtual prototype simulation of dump truck-haul road interactions, International Journal of Heavy Vehicle Systems, 15 (2008), 2-4, 416432(17).

[14] Novak-Marcinčin, J.: Application of the Virtual Reality Modelling Language in Automated Technological Workplaces Design, Engineering Review, 27 (2007), 1, pp. 1-6.

[15] Liu, B. J., Chen, C., Si, Y. F.: Application Research on Vehicle Steering Stability Based on ADAMS/CAR, Applied Mechanics \& Materials, 730 (2015), 289-292.

[16] Xu, M.: Simulation Analysis and Optimization on Rigid-flexible Coupling Vehicle Model Ride Comfort Based on ADAMS, MASTER DEGREE, Hefei University of Technology, China, 2013.

[17] Li, H., Zang, H., Cao, Y., He, S.: Virtual Prototyping of Climbing Mechanism in Vertical Pipeline Based on SolidWorks and 
MCS.ADAMS, in Education Technology and Computer Science (ETCS), 2010 Second International Workshop on, 2010, 99-102.

[18] Mahmoodi-Kaleibar, M., Javanshir, I., Asadi, K., Afkar, A., Paykani, A.: Optimization of suspension system of off-road vehicle for vehicle performance improvement, Journal of Central South University, 20 (2013), 4, 902-910.

[19] Li, Z. S., Wu, H. T., Liu, H. B.: The Dynamic Simulation of Contact Force between Wheels and Ground Based on ADAMS, Advanced Materials Research, 510 (2012), 437-441.

[20] Faik, S. Witteman, H.: Modeling of impact dynamics: A literature survey, in 2000 International ADAMS User Conference, 2000.

[21] Sui, W.: Research on Dynamics Simulation of Crawler Travelling Mechanics of Large Mining Excavator, M.S. thesis, May. JinLin University, ChangChun. China, 2007.
[22] Ling, J.: Optomal Design about Crawler Board of EBZ-135 Cantilever Type Roadheader, M.S. thesis, Jun. Taiyuan University of Technology, Taiyuan. China, 2010.

[23] GB/T 27694: Safety of industrial trucks-Test methods for measuring vibration. Beijing, China, 2011.

[24] Xiaoyang, Z., Beibei, S., Qinghong, S., Nan, C.: Vehicle and terrain interaction based on Adams Matlab co-simulation, Journal of Southeast University (English Edition), 25 (2009), 3, 335339.

[25] GB/T 4970: Method of running test-Automotive ride comfort. Beijing, China, 2009. 